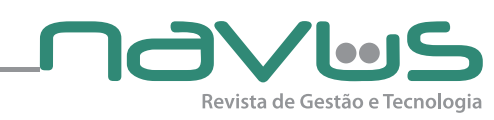

\title{
Diagnóstico de níveis de maturidade em gestão do conhecimento: centro de empreendedorismo inovador da Fundação CERTI
}

Fabíola da Rocha Borba ${ }^{1}$ Eduardo Costa Knoll ${ }^{2}$ Marilda Todescat ${ }^{3}$

\section{RESUMO}

Trabalhou-se no referente artigo com a Fundação Centros de Referência em Tecnologia Inovadora (CERTI), organização de referência no Brasil no desenvolvimento de soluções inovadoras para a sociedade, lidando com uma vasta e complexa rede de informações e conhecimento. Haja vista o grande porte da organização, o objetivo desta pesquisa foi diagnosticar os níveis de maturidade em Gestão do Conhecimento em um dos seus centros de referência: o Centro de Empreendedorismo Inovador (CEI). Essa justifica-se pela importância de tal centro no desenvolvimento e suporte ao empreendedorismo e inovação no estado de Santa Catarina. Metodologicamente, caracteriza-se como uma pesquisa exploratória e descritiva, pois busca identificar o nível de maturidade em GC do CEI. Este nível foi identificado a partir da aplicação do Diagnóstico de Níveis de Maturidade em GC, desenvolvido pela Asian Productivity Organization (APO). A partir da soma de cada critério da metodologia, enquadrou-se o CEI como estando no nível 2 de GC, significando que o centro está começando a reconhecer a necessidade de gerir o conhecimento ou já pode ser/estar no início de um projeto piloto. Além disso, foi possível realizar um levantamento dos pontos fortes e fracos de cada um dos critérios.

Palavras-chave: Gestão do Conhecimento. Organização do Conhecimento. Conhecimento. Níveis de Maturidade em GC.

${ }^{1}$ Graduanda em Administração - Universidade Federal de Santa Catarina - fabirborba@hotmail.com

${ }^{2}$ Graduando em Administração - Universidade Federal de Santa Catarina - eduardocostaknoll@gmail.com

${ }_{3}^{3}$ Doutora - Universidade Federal de Santa Catarina - marilda.t@ufsc.br 


\title{
1 INTRODUÇÃO
}

Atualmente, o conhecimento é o ponto-chave que possibilita às organizações gerarem inovação e atingirem seus objetivos com mais facilidade, o que torna a sua gestão um fator estratégico.

Escolheu-se a Fundação CERTI, organização de referência no estado de Santa Catarina em inovação, para realização do estudo de caso, visto que esta lida diretamente com uma vasta e complexa rede de informações e conhecimento, atuando no desenvolvimento de soluções inovadoras para a sociedade.

Haja vista o grande porte da organização, o trabalho dará enfoque em um dos seus centros de referência, o Centro de Empreendedorismo Inovador (CEI). Esse Centro atua com o desenvolvimento e suporte ao empreendedorismo e inovação no estado de Santa Catarina, tendo como propósito o desenvolvimento de:

\begin{abstract}
Soluções de referência para a promoção de empresas inovadoras, por meio da formação de um ecossistema inovativo com metodologias, ambientes e mecanismos que resultem na ampliação da competitividade das empresas e no alto impacto econômico, social, ambiental e tecnológico (CERTI, 2011, p. 21).
\end{abstract}

Partindo dos serviços oferecidos pelo CEI, e a ideia proposta por Kelley, Bosma e Amorós (2011), em que a economia permeada pela inovação é constituída pelos negócios mais intensivos em conhecimento, explicando, portanto, o crescimento do setor de serviços, percebe-se relevante para o próprio centro avaliar o seu nível de conhecimento por meio da metodologia sistematizada de Diagnóstico de Níveis de Maturidade da Gestão do Conhecimento, disponibilizada pela Asian Productivity Organization (AP0).

A identificação desse nível trará base para seus gestores perceberem se estão impulsionando corretamente e de forma produtiva a gestão do conhecimento entre suas equipes, a fim de oferecer seus serviços, potencializando a inovação no estado e sendo parte integrante da referência de inovação em que a Fundação é reconhecida.

Entende-se como imprescindível a presença de um alto nível de gestão do conhecimento dentro do Centro de Empreendedorismo Inovador da CERTI, pois este dá suporte para a inovação e empreendedorismo no estado de Santa Catarina e atua com uma vasta rede de informações e conhecimento. Além disso, recentemente houve uma grande rotatividade no Centro, correndo o risco de este ter perdido muito do conhecimento construído.

Dessa forma, a presente pesquisa teve como objetivo norteador elaborar um diagnóstico do nível dessa gestão para os dirigentes compreenderem se estão utilizando corretamente todo o conhecimento criado internamente. Além disso, poderá servir como base para futuros estudos de caso, no que se refere à construção de um plano de ação para a execução de uma gestão do conhecimento formalizada.

0 presente estudo torna-se relevante para a academia e para a empresa. Outro fato que contribui para isso, de acordo com as pesquisas feitas em periódicos, é a ausência de estudos anteriores que sugerem a identificação do nível de conhecimento em um Centro da CERTI, o que também demonstra a originalidade dessa abordagem.

0 artigo está dividido em 5 seções que delineiam o alcance do objetivo geral, partindo primeiramente por esta introdução, que justifica a pesquisa, seguida do resgate da fundamentação teórica existente sobre o tema, da descrição da metodologia utilizada, da apresentação e análise dos resultados e, por fim, das considerações finais.

\subsection{Objetivo geral}

Identificar o nível de maturidade da Gestão do Conhecimento no Centro de Empreendedorismo Inovador da Fundação Certi.

\subsection{Objetivos específicos}

a) Identificar os pontos fortes e fracos da Gestão do Conhecimento no Centro de Empreendedorismo Inovador da Fundação Certi.

b) Analisar o CEI como organização intensiva em Conhecimento. 


\title{
2 ORGANIZAÇÃO DO CONHECIMENTO
}

"A organização que for capaz de integrar eficientemente os processos de criação de significado, construção do conhecimento e tomada de decisão pode ser considerada uma organização do conhecimento" (CHOO, 2003, p. 3). 0 autor parte do princípio de que a informação gera uma ação e, consequentemente, uma escolha de um curso racional, possibilitando a identificação desse processo dentro da organização em diferentes fases: Criação de significado, Construção de conhecimento, Tomada de decisão, conforme Figura 1.

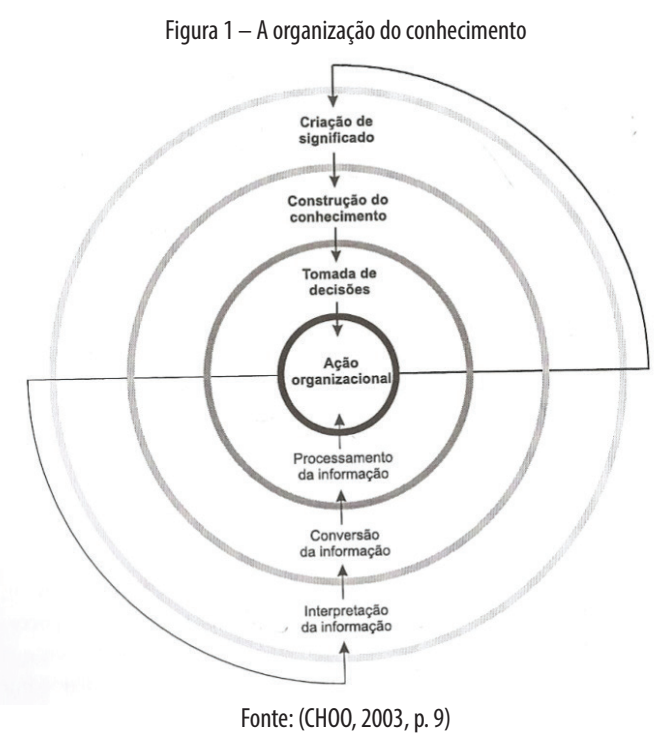

Segundo Choo (2003), a informação, representada pela seta, advinda de seu ambiente, segue um fluxo contínuo, passando por todas as três fases, em que a informação é interpretada, convertida e processada, gerando uma ação organizacional. Durante todo esse processo, ela sofre transformações e pode gerar mudanças na organização e no ambiente em que ela está inserida. Percebe-se, também, que as três áreas de uso da informação são de fato processos interligados e possuem atividades integradas de retroalimentação.

\begin{abstract}
Administrando os recursos e processos de informação, a organização do conhecimento é capaz de: adaptar-se às mudanças do ambiente no momento adequado e de maneira eficaz; empenhar-se na aprendizagem constante, o que inclui desaprender pressupostos, normas e crenças que perderam validade; mobilizar o conhecimento e a experiência de seus membros para gerar inovação e criatividade; focalizar seu conhecimento em ações racionais e decisivas. (CHOO, 2003, p. 31).
\end{abstract}

Fica claro o papel vital que a informação desempenha na organização, sendo a sua utilização o fator decisivo para alcançar seus objetivos. 0 desempenho de uma organização está ligado ao modo como ela utiliza e integra a informação no dia a dia e em todas as suas áreas.

A criação de significado é responsável por interpretar, selecionando e retendo as informações, dando a elas sentido e eliminando não integralmente a ambiguidade. A construção de novos conhecimentos é o cerne do fluxo, é nessa etapa que os novos conhecimentos são criados por meio da conversão e compartilhamento dos conhecimentos disponíveis inerentes nas pessoas, processos e cultura organizacional. A tomada de decisão é caracterizada pela busca da solução racional e lógica para o problema, com base nos novos conhecimentos, de acordo com regras e rotinas. Criação de significado, construção de conhecimento e tomada de decisão "[...], os três modos de informação se sobrepõem. Na verdade cada processo fornece os elementos essenciais de que o outro precisa para funcionar" (CHOO, 2003, p. 50).

\section{1 Modelo de Maturidade de GC}

A GC sempre existiu nas organizações, sendo elas: voluntária ou involuntária, estruturada ou não; entretanto, para transformá-la em vantagem competitiva, é necessária a implementação de um processo 
estruturado e coordenado de GC.

Entender como a informação e o conhecimento fluem pela organização é essencial para a melhoria contínua de toda a organização; todavia, apenas a compreensão disso não torna factível a implementação do processo estruturado de GC, surge a necessidade de criar ferramentas e modelos para mensurar a GC nas organizações.

A crescente competitividade no mundo dos negócios, motivada principalmente pela globalização da economia mundial e a revolução tecnológica, principalmente a partir da década de 90, é uma característica ambiental que alguns autores denominam "Era da Informação". Neste novo ambiente competitivo e mutatório, observa-se uma busca acelerada por métodos, modelos e ferramentas que conduzam as organizações à excelência de seus bens e serviços (FIORAVANTE; LUCCA, 2005, p. 1).

Atualmente o Knowledge Management Maturity Model é aplicado em diversas organizações para mensuração da GC.

Segundo Ehms e Langen (2002), este modelo consiste na definição de uma estrutura conceitual de cinco níveis de GC, que refletem o valor dado pela organização para as principais áreas relacionadas ao conhecimento (Figura 2).

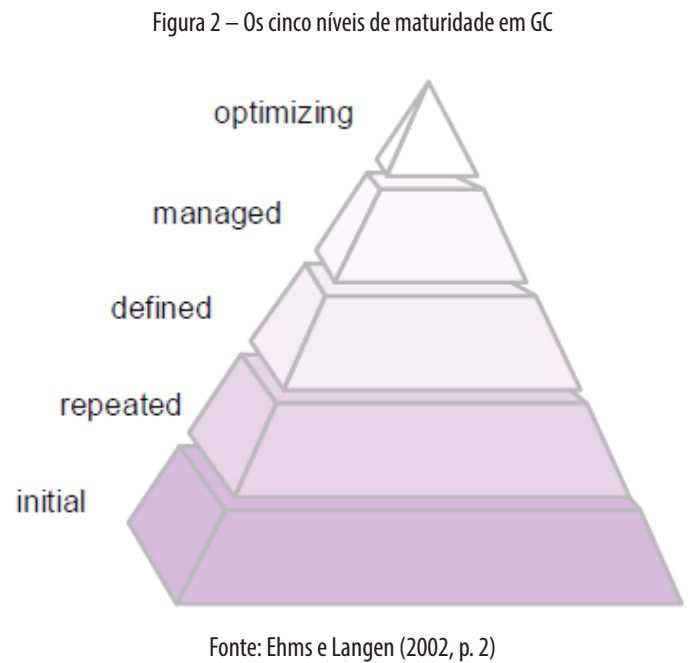

Cada nível apresenta um padrão de GC na organização, que possibilita a compreensão e o planejamento para melhorias, alinhando aos objetivos estratégicos. "O Modelo de Maturidade de GC ajuda a organização a avaliar o seu progresso relativo na implementação dessa gestão em um nível mais detalhado. Pode ser descrito como um conjunto estruturado de elementos que descreve os diferentes níveis de maturidade" (APO, 2010a, p. 71).

Conforme Ehms e Langen (2002), os níveis apresentam as seguintes características:

- Nível de Maturidade "Initial": Os processos não são conscientemente controlados, atividades bemsucedidas relacionadas com o conhecimento são vistas como um golpe de sorte e não como o resultado da definição de metas e planejamento.

- Nível de Maturidade "Repeated": A organização tem reconhecido a importância das atividades de GC para o seu negócio. Processos organizacionais são parcialmente descritos como tarefas de GC e, em virtude de ideias individuais de "pioneiros em GC", existem projetos-piloto de GC.

- Nível de Maturidade "Defined": Atividades estabelecidas e praticadas que efetivamente dão apoio à GC em partes separadas da organização. Essas atividades são integradas nos processos de trabalho do dia a dia e sistemas de técnicas correspondentes são mantidas.

- Nível de Maturidade "Managed": Indicadores relativos à eficiência dessas robustas atividades de GC são regularmente medidos. As atividades são garantidas em longo prazo por toda a organização e compatíveis com sistemas sociotécnicos de GC.

- Nível de Maturidade "Optimizing": Os instrumentos de medição de GC estão combinados com outros instrumentos para o controle estratégico. Não há desafios que não possam ser resolvidos com as 
ferramentas GC estabelecidas.

Atualmente, existem diversas variações desse modelo de maturidade que vem evoluindo e adaptando-se às novas descobertas, sempre com o objetivo de conseguir um diagnóstico mais exato da GC nas organizações.

No presente estudo, utilizou-se a ferramenta adaptada de diagnóstico de maturidade GC, desenvolvida pela APO.

O Modelo de Maturidade de GC é para ser usado quando uma organização quer entender o nível de maturidade de suas práticas de GC. 0 modelo deve ser utilizado após uma avaliação de GC da organização. A ferramenta de avaliação APO KM pode ser utilizada para esta finalidade. A ferramenta identifica os pontos fortes e áreas de melhoria das práticas de GC de uma organização (APO, 2010b, p. 16).

Esta ferramenta de diagnóstico apresenta cinco níveis de Maturidade em GC.

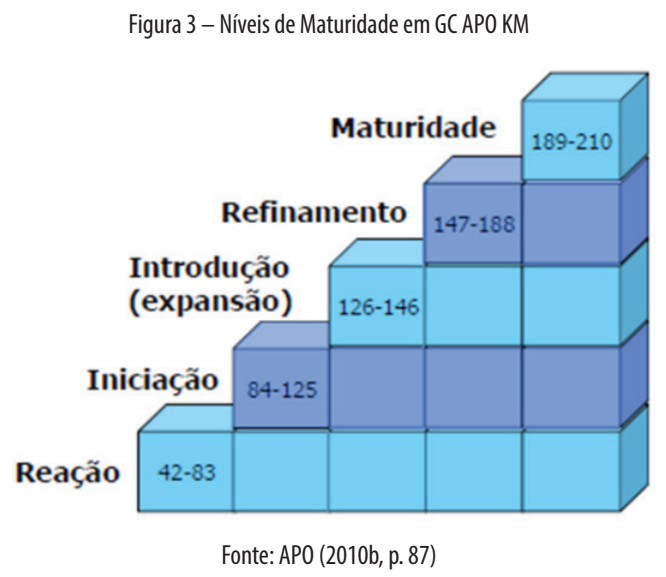

Segundo APO (2010b), existem cinco níveis de Maturidade em GC, sendo do menor nível para o maior: (1) Reação, (2) Iniciação, (3) Expansão, (4) Controle e (5) Maturidade. 0 significado de cada um dos cinco níveis é exposto a seguir:

a) Nível 1 Reação: A organização não tem conhecimento de que GC é e sua importância no aumento da produtividade e competitividade.

b) Nível 2 Iniciação: A organização está começando a reconhecer a necessidade de gerir o conhecimento ou já pode ser o início de um projeto-piloto GC.

c) Nível 3 Expansão: GC está totalmente implementado e implantado.

d) Nível 4 Controle: Controle de implementação do GC é continuamente avaliado para a melhoria contínua.

e) Nível 5 Maturidade: GC está totalmente integrado dentro da organização.

\section{METODOLOGIA}

A metodologia consiste em detalhar todos os procedimentos adotados para a realização da pesquisa e, portanto, para responder o objetivo desta. De acordo com a natureza da pesquisa, onde tem-se o intuito de obter como resultado algo quantificável partindo-se de uma ferramenta sistemática, enquadra-se esta pesquisa como descritiva e qualitativa.

O seguinte trabalho é caracterizado também como um estudo de caso, pois a pesquisa foi feita no CEI (Centro de Empreendedorismo Inovador).

Para a coleta de dados foi aplicado um questionário online, através do formulário do Google , sendo realizada uma adaptação do Diagnóstico de Níveis de Maturidade em GC, desenvolvido pela APO. Este instrumento está organizado em 07 critérios: liderança em GC, Processos, Pessoas, Tecnologia, Processos de GC, Aprendizagem e Inovação e Resultados de GC. Estes critérios foram avaliados por meio de 42 perguntas fechadas com respostas em escala de 1 a 5 , sendo 1 para o nível mínimo e 5 para o nível máximo de grau de maturidade. 0 tratamento desses dados foi quantitativo.

O universo de estudo foram os 18 funcionários do CEI, perfazendo uma amostra censitária. Como o 
preenchimento não foi de caráter obrigatório, obtivemos o total de 13 respondentes.

0 seguinte trabalho se limita a atuar apenas no CEI, com dados referentes ao primeiro semestre do ano de 2013, além das limitações impostas pela própria ferramenta de diagnóstico.

\section{APRESENTAÇÃO E ANÁLISE DOS RESULTADOS}

Para a apresentação dos resultados da pesquisa, e um melhor entendimento de como o raciocínio foi traçado até, por fim, chegar-se ao nível de gestão do conhecimento do CEI. Apresenta-se primeiramente uma breve descrição do Centro e, a seguir, a análise dos resultados de cada critério do questionário adaptado da ferramenta de nível de gestão do conhecimento do APO.

\subsection{Centro de Empreendedorismo Inovador}

O Centro de Empreendedorismo Inovador (CEI) caracteriza-se como um dos centros de referência que fazem parte do corpo do organograma da Fundação CERTI, estando abaixo das superintendências, que, por sua vez, estão subordinadas ao Conselho de Curadores.

O CEI é constituído, atualmente, por dezoito funcionários que desenvolvem "soluções diferenciadas para promoção da inovação em uma região ou empresa" (CERTI, 2013), pela implementação de projetos de apoio ao empreendedorismo inovador como: incubadoras de ideias e empresas, parques tecnológicos e outros que "reforçam o processo de inovação e a ampliação da competitividade frente ao mercado global" (CERTI, 2013).

Suas competências e soluções inovadoras são definidas em três frentes. A primeira refere-se a ambientes e mecanismos de inovação, que atuam com a concepção e operação de ambientes e mecanismos promotores da inovação, parques tecnológicos para inovação, incubadoras de empresas de base tecnológica, escritórios regionais para promoção da inovação, núcleos de inovação tecnológica e centros tecnológicos e de inovação.

A segunda competência/solução são os ecossistemas de inovação, que atuam no desenvolvimento de projetos de alto valor agregado para estruturação do Ecossistema de Inovação, clusters e polos de inovação e desenvolvimento tecnológico regional. E, por último, a Inovação Corporativa, que engloba soluções de gestão da inovação e de sistemas para promoção e suporte da inovação na empresa, no planejamento estratégico da Inovação Corporativa e no empreendedorismo e venture corporativo.

Todo o desenvolvimento do trabalho do centro é voltado ao atendimento de empresas de base tecnológica, governo municipal, estadual e federal, associações e federações da indústria e empresas inovadoras, tendo destaque em cinco projetos executados segundo suas competências já mencionadas. Esses projetos são a concepção e operacionalização do Programa Inova@SC da SDS/FAPESC, operacionalização do projeto Sinapse da Inovação, promovido pela FAPESC, planejamento de parques tecnológicos e da Inovação, planejamento e implantação de incubadoras e empresas inovadoras, e capacitação de gestores de incubadoras no modelo CERNE da ANPROTEC.

\subsection{Análise dos Resultados}

Nesta seção, serão apresentados os resultados da coleta de dados, por meio da descrição e análise de cada um dos sete critérios utilizados na ferramenta de diagnóstico do nível de GC da APO.

\subsubsection{Liderança em Gestão do Conhecimento}

O critério "Liderança em GC" avalia a capacidade de liderança da organização para responder aos desafios de uma economia e de uma sociedade baseada no conhecimento, por meio de políticas e estratégias de GC.

De acordo com o Gráfico 1, das sete perguntas referentes a esse tema a que obteve maior pontuação foi a de número 4, que trata sobre a existência de uma política de proteção do conhecimento, evidência da força do centro nesse quesito. Já a questão de menor pontuação refere-se à existência de orçamento alocado diretamente para a GC. Aproximadamente 84\% dos respondentes optaram pelas respostas "as ações descritas são muito mal realizadas ou ainda não são realizadas" e "as ações descritas são mal realizadas", apontando, portanto, para uma falta de investimento ou até mesmo desconhecimento por parte dos funcionários.

Além disso, a questão 2 também chama a atenção, já que aproximadamente $77 \%$ dos respondentes optaram pelas opções mais baixas de resposta, ao mencionarem que não há uma estrutura formal responsável 
pela GC ou é mal realizada.

O Gráfico 1 ilustra a situação do CEI no critério de Liderança em GC, fazendo uma comparação entre as pontuações de cada pergunta.

Gráfico 1 - Liderança em gestão do conhecimento

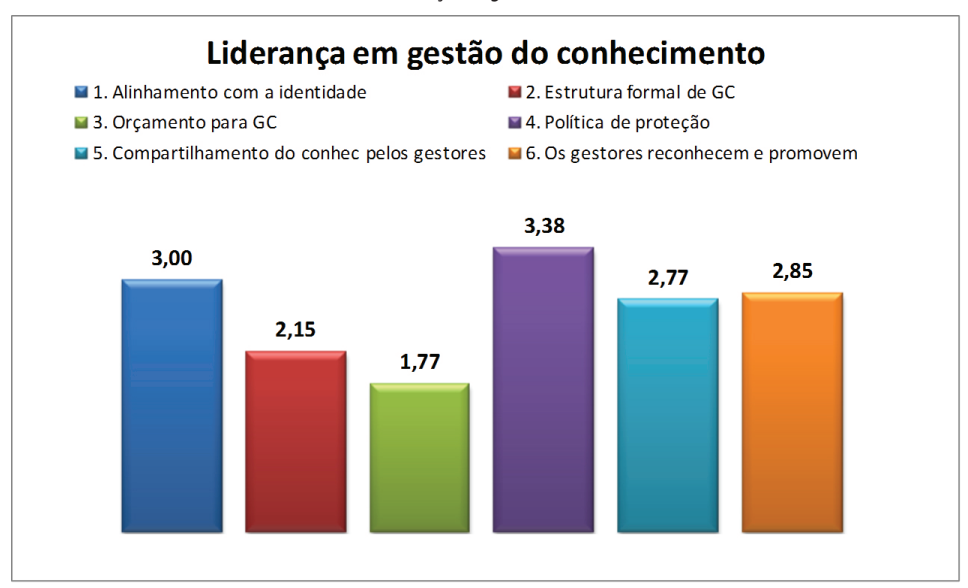

Fonte: Dados Primários. Elaborado pelos autores (2013)

Percebe-se, desse modo, que, apesar de o Centro possuir uma pontuação baixa relativamente à alocação dos recursos e à existência de uma estrutura formal de GC, essa se encontra em níveis mais altos quanto às políticas de proteção e do alinhamento da GC com a sua identidade organizacional.

\subsubsection{Processos}

Em "processos", é verificado como o conhecimento é utilizado na gestão, implementação e melhoria dos processos de trabalhos essenciais da organização.

Analisando-se o Gráfico 2, é possível destacar uma baixa pontuação para a questão 10, referente à existência de um sistema organizado para gerenciar situações de crise ou imprevistos que asseguram a continuidade das operações, prevenção e recuperação. A assertiva 12 questiona se o centro avalia e melhora continuamente seus processos para alcançar melhor desempenho; nesta questão, também foi observada uma baixa pontuação.

Dentre as questões que receberam maior pontuação, é possível destacar a 8 e a 11, que abordam, respectivamente, a modelagem dos sistemas de trabalho e processos para agregar valor ao cliente, e promover o alto desempenho institucional e com a implementação e gerenciamento dos processos para assegurar $\mathrm{o}$ atendimento das necessidades do cliente e a manutenção dos resultados da organização.

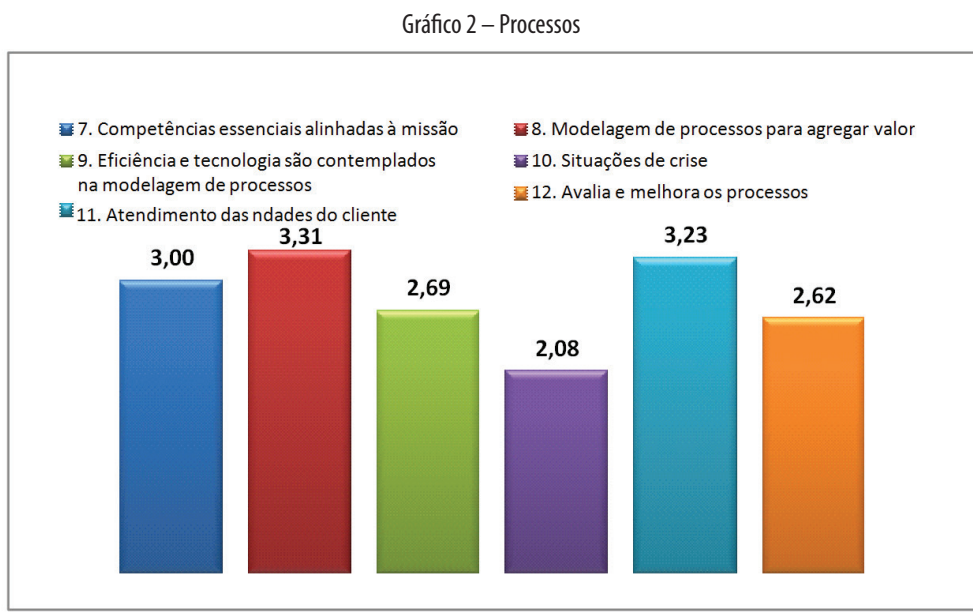

Fonte: Dados Primários. Elaborado pelos autores (2013) 
É possível analisar que as questões desse critério, que envolvem agregação de valor ao cliente e atendimento de suas necessidades, receberam pontuação maior do que as dos processos internos do centro, evidenciando uma preocupação maior com aqueles processos que afetam diretamente o cliente. Isso acontece em razão da variedade de projetos que ocorrem simultaneamente no CEI, necessitando dar prioridade ao cliente e sua satisfação antes mesmo dos processos internos, haja vista a variável "tempo".

\subsubsection{Pessoas}

Neste critério, examina-se a capacidade da organização de criar e manter uma cultura baseada no conhecimento organizacional, um ambiente de compartilhamento de conhecimento colaborativo, uma organização de aprendizagem, na qual as pessoas são o fator-chave.

Quanto aos resultados desse critério, a pontuação de cada pergunta praticamente se igualou, como mostra o Gráfico 3, sendo esses valores próximos à pontuação 2. A discrepância maior se dá com a questão 18, apresentando uma pontuação um pouco maior para o quesito de formação de pequenas equipes/grupos e estrutura por processos/projetos para enfrentar as preocupações e os problemas no local de trabalho.

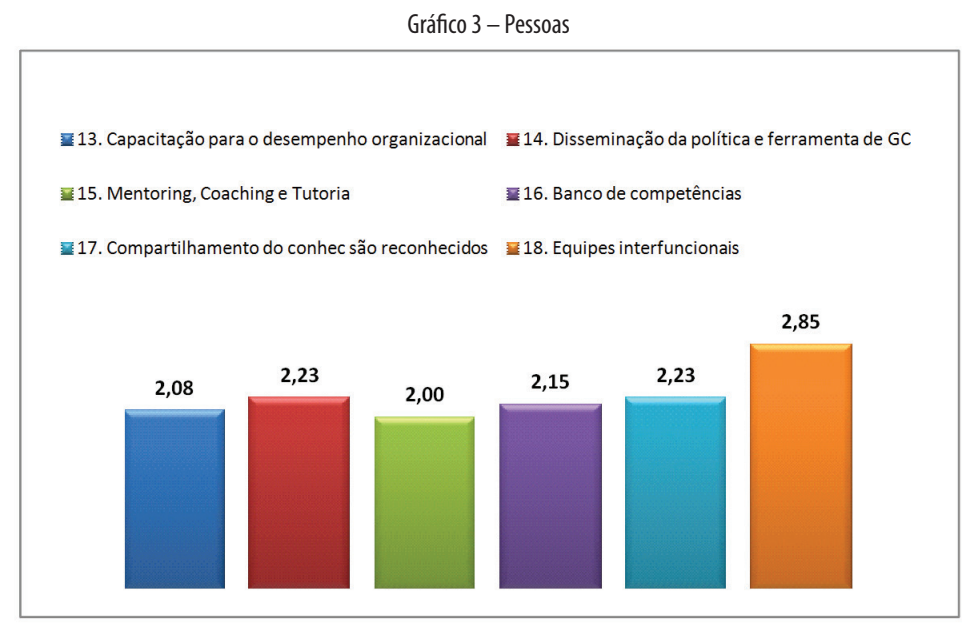

Fonte: Dados Primários. Elaborado pelos autores (2013)

O soma das médias desse critério é uma das mais baixas, representando uma deficiência aparente. Apesar de o Centro ter como cultura a formação de equipes interfuncionais para o desenvolvimento de projetos, tal atividade é feita de forma não planejada, não apresentando uma estrutura de banco de competências, coaching, tutorial e capacitação estruturados.

\subsubsection{Tecnologia}

O critério "tecnologia" analisa a capacidade da organização para desenvolver e entregar soluções baseadas em conhecimentos e criar e manter um ambiente de compartilhamento de conhecimentos. Além disso, avalia a qualidade dos sistemas de hardware e software, internet, intranet, site, portal, gerenciamento de conteúdo.

Esse critério apresenta as pontuações mais altas, evidenciando um nível mais avançado para o apoio à gestão do conhecimento. Sua pontuação total é de 23, apontando que está em um nível mais maduro, já que se aproxima do máximo, 30.

Como já esperado, em virtude da natureza das atividades do CEI e das estruturas encontradas na grande maioria das empresas atuais, as perguntas mais pontuadas foram a 21 e 22 em que se analisa o acesso a computador, internet, intranet e e-mail. 


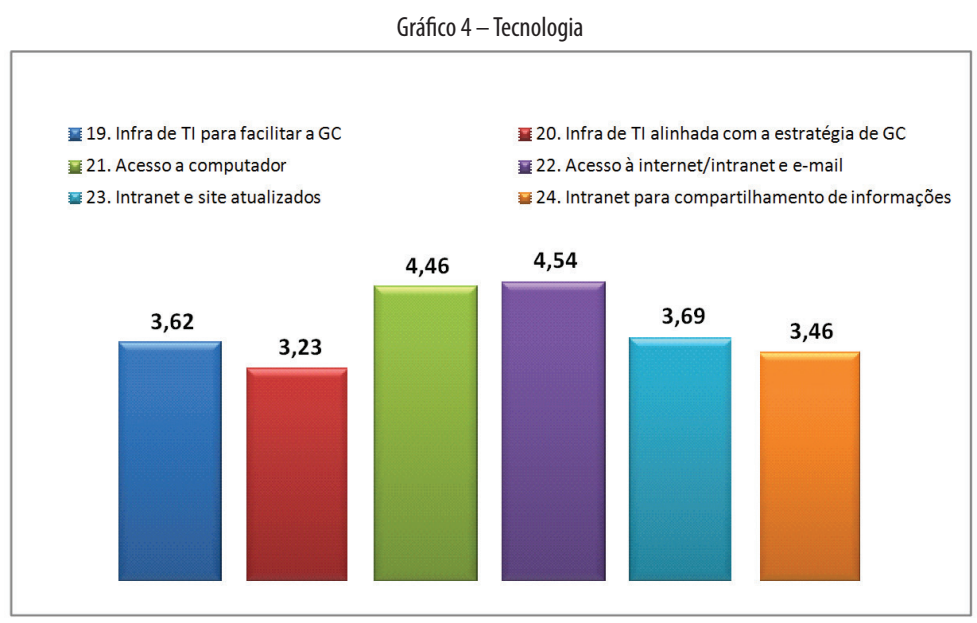

Fonte: Dados Primários. Elaborado pelos autores (2013)

\subsubsection{Processos de conhecimento}

O critério "Processos de conhecimento" tem o intuito de avaliar a capacidade da organização em gerir e maximizar o valor do capital intelectual da organização, desenvolver e oferecer programas e serviços baseados no conhecimento e gerenciar clientes, e compartilhar e aplicar o conhecimento relevante para os clientes, fornecedores, parceiros e outras partes interessadas.

Apesar de a escala do Gráfico 5 aparentar visualmente uma discrepância entre as pontuações das questões, numericamente, pode-se perceber que há um equilíbrio entre elas, aproximando-se de 2,6.

A pergunta que mais se acentua positivamente é a referente ao uso do benchmarking dentro e fora da organização, e seus resultados utilizados para melhorar o desempenho do centro e criar novos conhecimentos. Observa-se que a atividade de benchmarking atualmente faz parte de um dos projetos que possui relação direta com o alcance das metas do CEI.

Por outro lado, as perguntas que apresentam menor valor são "retenção do conhecimento dos funcionários que saem" e "compartilhamento das melhores práticas". Essas são ações que ocorrem dependendo do perfil e preocupação de cada funcionário, sem apresentar uma estrutura formalizada.

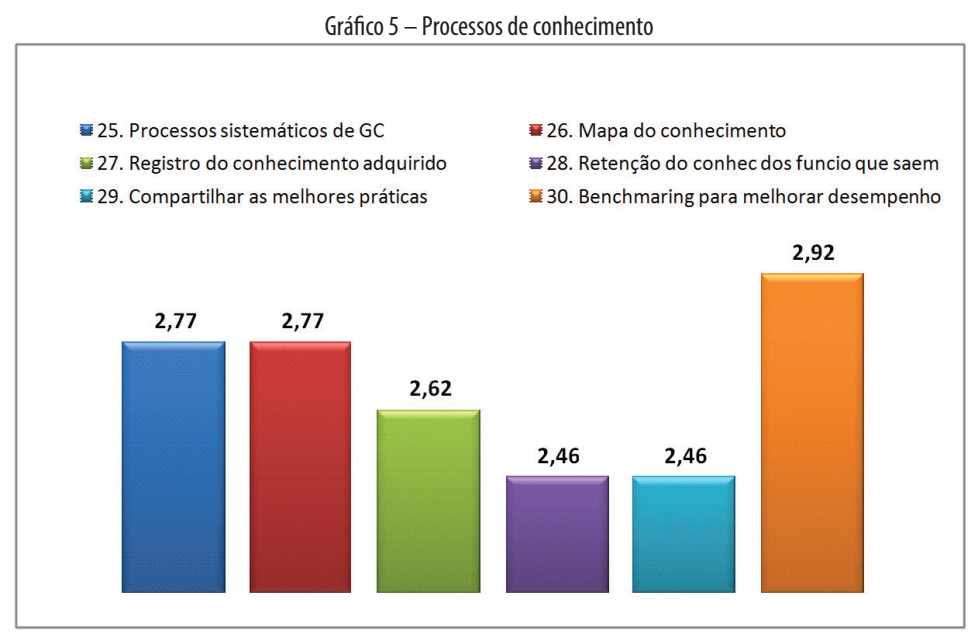

Fonte: Dados Primários. Elaborado pelos autores (2013)

\subsubsection{Aprendizagem e Inovação}

Esse critério determina a capacidade da organização para incentivar, apoiar e reforçar a aprendizagem e a inovação por meio de processos de conhecimentos sistemáticos. Avalia o incentivo de valores de aprendizagem e inovação, com a abertura à novas ferramentas e técnicas de gestão, às novas ideias e aos 
erros, que devem ser vistos como oportunidades de aprendizagem.

A partir disso, percebe-se que as médias do CEI no seguinte critério mostram-se uma das mais altas, sendo ultrapassado apenas pelo critério tecnologia. Isso muito provavelmente se dá pela forte característica de inovação que os projetos do centro carregam, exigindo um alto grau de inovação e, consequentemente, de aprendizagem.

Em contrapartida, vê-se no Gráfico 6 que a pontuação mais baixa foi na questão referente a considerar a atitude de assumir riscos e o fato de cometer erros como oportunidades de aprendizagem. Já a questão mais evidente e maior pontuada pelos funcionários foi a referente ao incentivo para trabalhar com outras pessoas e compartilhar informação. Apesar de não possuir uma forma estruturada para tanto, o trabalho com equipes multifuncionais faz parte da cultura do Centro.

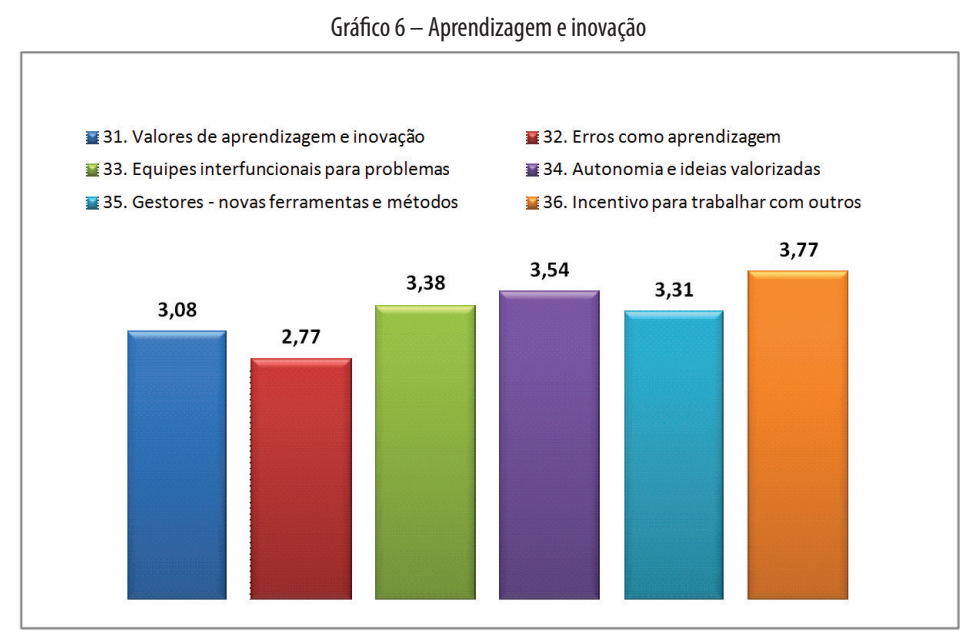

Fonte: Dados Primários. Elaborado pelos autores (2013)

\subsubsection{Resultados da gestão do conhecimento}

Esse critério mede a capacidade da organização de aumentar o valor para os clientes por meio de novos e melhores produtos e serviços, aumentar a produtividade e eficácia na utilização dos recursos, como resultado de prendizagem e inovação.

As questões mais pontuadas são a 37 e 38, que avaliam a existência de histórico de indicadores de GC e de mudanças. Em contrapartida, as pontuações mais baixas são em relação à melhoria dos indicadores de qualidade de serviços, eficiência, efetividade social e desenvolvimento e inovação em função da gestão do conhecimento.

Vê-se que, nesse critério, houve uma discrepância entre as respostas dos funcionários, talvez pelo não entendimento ou visões diferentes sobre a mesma questão. 0 Centro possui um controle mediante indicadores diversos; porém, nenhum específico para a avaliação das ações de gestão do conhecimento. Nesse caso, muitos podem ter tido uma interpretação própria sobre a influência das ações informais de GC em seus indicadores. 
Gráfico 7 - Resultados da gestão do conhecimento

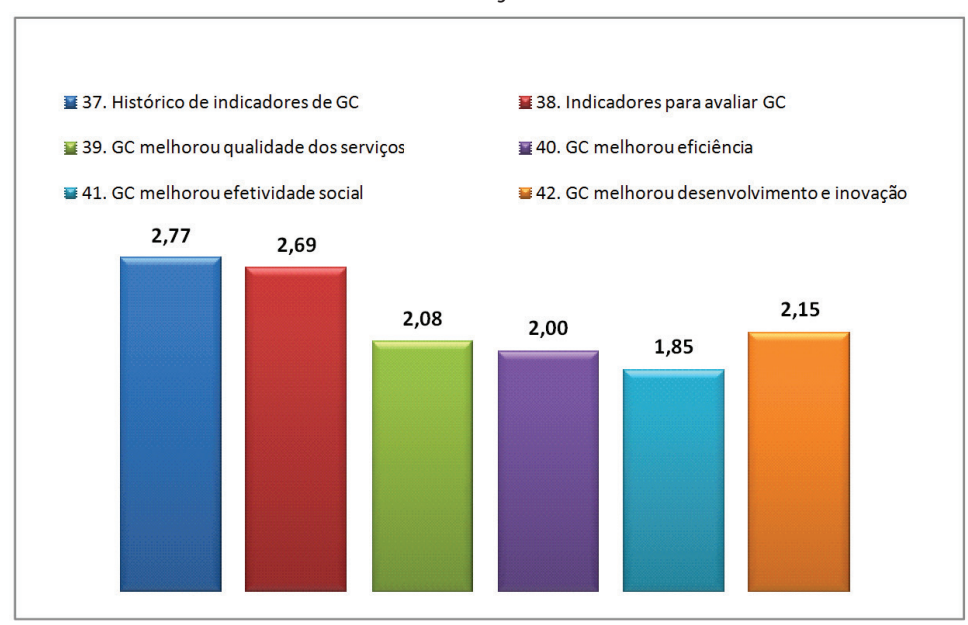

Fonte: Dados Primários. Elaborado pelos autores (2013)

Levantando-se os pontos fracos e fortes referentes à pontuação das questões de cada critério, gera-se a Quadro 1. Em alguns casos as médias eram tão próximas que não era possível destacar um ponto fraco.

Quadro 1 - Pontos fortes e fracos de cada critério

\begin{tabular}{|c|c|c|}
\hline Critério & Pontos fortes & Pontos fracos \\
\hline \multirow[t]{2}{*}{ Liderança em GC } & Política de proteção & Orçamento alocado para a GC \\
\hline & & Estrutura formal de GC \\
\hline \multirow[t]{2}{*}{ Processos } & Modelagem de processos para agregar valor ao cliente & $\begin{array}{l}\text { Sistema organizado para gerenciar situações de crise ou } \\
\text { imprevistos }\end{array}$ \\
\hline & $\begin{array}{l}\text { Implementação e gerenciamento dos processos para } \\
\text { assegurar } 0 \text { atendimento das necessidades do cliente }\end{array}$ & $\begin{array}{l}\text { Avaliação e melhoria contínua dos processos para alcançar } \\
\text { mehor desempenho }\end{array}$ \\
\hline Pessoas & $\begin{array}{l}\text { Formação de pequenas equipes/grupos e estrutura por } \\
\text { processos/projetos para enfrentar as preocupações e os } \\
\text { problemas no local de trabalho }\end{array}$ & I \\
\hline Tecnologia & Acesso a computador, internet, intranet e e-mail & / \\
\hline \multirow[t]{2}{*}{ Processos de conhecimento } & $\begin{array}{l}\text { Benchmarking dentro e fora da organização e seus resul- } \\
\text { tados utilizados para melhorar o desempenho do centro e } \\
\text { criar novos conhecimentos }\end{array}$ & Retenção do conhecimento dos funcionários que saem \\
\hline & & Compartilhamento das melhores práticas \\
\hline Aprendizagem e inovação & $\begin{array}{l}\text { Incentivo para trabalhar com outras pessoas e comparti- } \\
\text { Ihar informação }\end{array}$ & $\begin{array}{l}\text { Considerar a atitude de assumir riscos e o fato de cometer } \\
\text { erros como oportunidades de aprendizagem }\end{array}$ \\
\hline Resultados da GC & $\begin{array}{l}\text { Existência de histórico de indicadores de GC e de } \\
\text { mudanças }\end{array}$ & $\begin{array}{l}\text { Melhoria dos indicadores de qualidade de serviços, eficiência, } \\
\text { efetividade social e desenvolvimento e inovação em função } \\
\text { da gestão do conhecimento }\end{array}$ \\
\hline
\end{tabular}

Fonte: Dados Primários. Elaborado pelos autores (2013)

\section{CONSIDERAÇÕES FINAIS}

Com base na metodologia de diagnóstico do nível de GC da APO, pode-se fazer o levantamento dos critérios, dentre os sete trabalhados, identificando os critérios mais e menos pontuados, assim como uma análise entre as questões que o compõem.

Os critérios com maior pontuação foram o de "tecnologia" e o de "aprendizagem e inovação", indo ao encontro do propósito do Centro, que é desenvolver: 
soluções de referência para a promoção de empresas inovadoras, por meio da formação de um ecossistema inovativo com metodologias, ambientes e mecanismos que resultem na ampliação da competitividade das empresas e no alto impacto econômico, social, ambiental e tecnológico (CERTI, 2011, p. 22).

Retoma-se, aqui, a afirmação de Choo (2003), a qual relata que o conhecimento reside na mente dos indivíduos, e esse conhecimento pessoal precisa ser convertido em conhecimento que possa ser partilhado e transformado em inovação. Portanto, esse é um dos caminhos para alcançar o propósito do CEI.

No Gráfico 8, é possível ainda se ter um panorama do nível de cada um dos critérios.

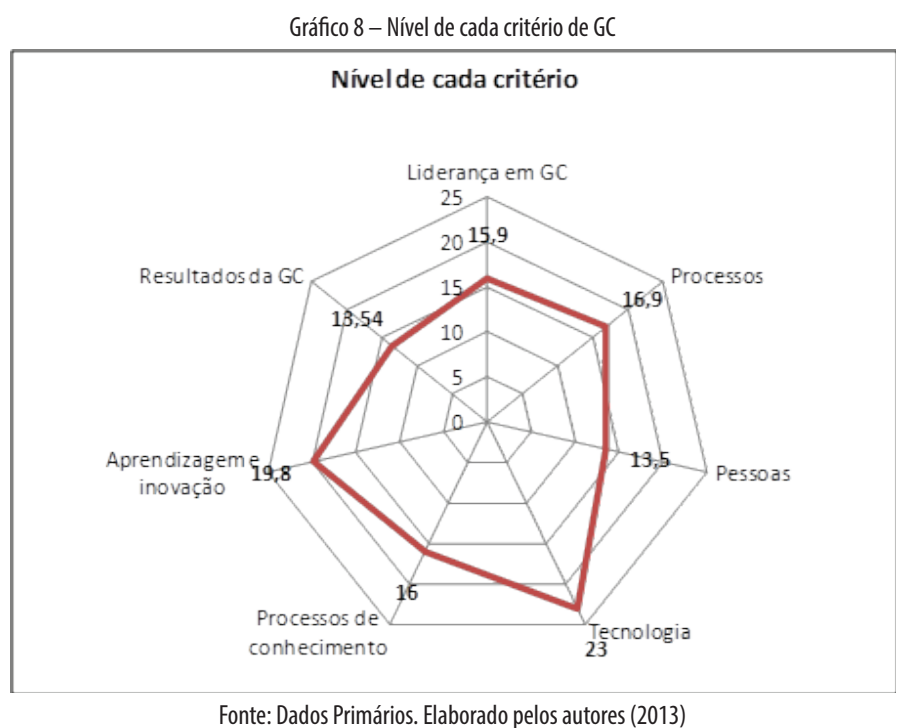

A soma de todas as médias dos sete critérios $(118,8)$ enquadra o Centro de Empreendedorismo Inovador (CEI) no nível 2, dos cinco estabelecidos pela ferramenta do APO. Isso significa que a organização está começando a reconhecer a necessidade de gerir o conhecimento ou já pode ser/estar no início de um projeto-piloto.

De acordo com Choo (2003), no estágio inicial da criação de significado (primeira etapa para tornarse uma organização do conhecimento), a organização recebe constantemente informações do ambiente, de diferentes fontes, e cabe ao(s) indivíduo(s), com processos e métodos estruturados, interpretarem, selecionarem e reterem os dados, transformando em informações para guiar a construção de conhecimento e a tomada de decisão.

Foi possível identificar que, apesar de o Centro não possuir uma estrutura formal responsável pela gestão do conhecimento, algumas práticas já estão incorporadas, como estruturas tecnológicas, política de proteção do conhecimento, incentivo para trabalhar com outras pessoas, modelagem e implementação de processos para agregar valor ao cliente e atender a suas necessidades, formação de pequenas equipes/ grupos e estrutura por processos/projetos para enfrentar as preocupações e os problemas no local de trabalho.

Claramente, há pontos em que o Centro deve trabalhar a fim de ajustar e potencializar a estrutura formal de GC, como: a alocação de recursos, avaliação e melhoria contínua dos processos, compartilhamento das melhores práticas, retenção do conhecimento dos funcionários que saem do centro. Também considerar a atitude de assumir riscos e o fato de cometer erros como oportunidades de aprendizagem.

0 critério "pessoas" apresenta o score mais baixo, causando estranheza já que o critério "aprendizagem e inovação" mostrou-se elevado; esse aspecto requer uma maior reflexão e análise. Choo (2003) corrobora, afirmando que os processos definem como os dados são obtidos, sua precisão e confiabilidade são indispensáveis, a cultura organizacional, sendo uma força tanto formal quanto informal, define como as ideias são compartilhadas. 0 mesmo também afirma que a cultura é responsável pelas redes de conexões da empresa, por onde a lógica dominante se estabelece e as perspectivas de análise se dão, por meio de consenso, coerência ou clareza.

Além disso, para que a GC seja o máximo possível alinhada aos objetivos e propósitos do CEI, é necessário que seja utilizado o histórico dos indicadores e os atuais utilizados para alinhar a gestão do 
conhecimento, transformando-a em resultados palpáveis e cada vez mais rentáveis, fechando o ciclo da gestão do conhecimento e fortalecendo a base para a inovação e competitividade do CEI.

Nonaka e Takeuchi (1995) sustentam essa ideia afirmando que a construção do conhecimento está intrinsecamente ligada à inovação e novas capacidades, sendo aplicado diretamente nos produtos e serviços, ou mesmo aos processos e métodos da empresa. Ambos, inovação e novas capacidades podem fornecer uma melhora no desempenho organizacional e uma vantagem competitiva.

\section{DIAGNOSIS OF MATURITY LEVELS IN KNOWLEDGE MANAGEMENT: INNOVATIVE ENTREPRENEURSHIP CENTER FOUNDATION CERTI}

\section{ABSTRACT}

The present article is an analysis of the complex network of information and knowledge involved in processes within the Foundation of the Centers of Reference in Innovative Technology (CERTI), reference organization on the development of innovative solutions for society in Brazil. Due to the great size of the organization, the objective of this research was to diagnose the maturity levels in Knowledge Management in one of its excellence centers: the Center for Innovative Entrepreneurship (CEI). This is justified by the importance of such center in the development and support of entrepreneurship and innovation in the state of Santa Catarina. Methodologically, this research is characterized as exploratory and descriptive: for it seeks to identify the level of maturity in the GC CEI. This level was identified from the application of the Levels of Maturity GC Diagnostic, developed by the Asian Productivity Organization - APO. From the sum of each criteria of the methodology, the CIS was fitted as being at level 2 GC, meaning that the center is beginning to recognize the need to manage knowledge or may already in the start of a pilot project. Moreover, it was possible to review the progress in strengths and weaknesses of each of the criteria.

Keywords: Knowledge Management . Knowledge Organization . Knowledge . Maturity Levels in GC.

\section{REFERÊNCIAS}

ASIAN PRODUCTIVITY ORGANIZATION (APO). Knowledge ManagementTools and Techniques Manual. [2010a]. Disponível em:< http://www.apo-tokyo.org/publications/files/ind-43-km_tt-2010.pdf>. Acesso em: 08 jul. 2013.

ASIAN PRODUCTIVITY ORGANIZATION (APO). Knowledge Management: Facilitators' Guide. [2010b]. Disponível em:< http://www.apo-tokyo.org/00e-books/IS39_APO KM-FG/IS-39_APO-KM-FG.pdf >. Acesso em: 08 jul. 2013.

BASSI, L. J.; CORTADA, J. W.; WOODS, J. A. Measuring knowledge management effectiveness: Harnessing the power of intellectual capital. Madison: CWL Publishing Enterprises, 1999.

CENTROS DE REFERÊNCIA EM TECNOLOGIAS INOVADORAS (CERTI). Relatório de atividades 2011. [2011]. Disponível em: <http://issuu.com/certi/docs/relatorio_atividades_certi_2011?e=8288365/>. Acesso em: 18 out. 2013.

CENTROS DE REFERÊNCIA EM TECNOLOGIAS INOVADORAS (CERTI). Solução inovadora: Sinapse da inovação. [2013]. Disponível em: <http://www.certi.org.br/projetos-inovadores/sinapse-da-inovacaofapesc.html>. Acesso em: 18 out. 2013.

EHMS, K.; LANGEN, M. Holistic Development of Knowledge Management with KMMM. [2002]. Disponível em:<http://www.kmmm.org/objects/kmmm_article_siemens_2002.pdf>. Acesso em: 08 jul. 2013. 
FIORAVANTE, Fabinana; LUCCA, Giancarlo. Uma proposta de indicadores de desempenho para gestão do conhecimento de uma instituição de ensino superior. In: Simpósio de Engenharia de Produção (SIMPEP), 12., 2005, Bauru. Anais do XII SIMPEP. Bauru: UNESP, 2005. p. 1-12.

KELLEY, D. J.; BOSMA, N.; AMORÓS, J. E. Global Entrepreneurship Monitor (GEM). Babson: Universidad Del desarollo, 2001.

NONAKA, I; TAKEUCHI H. The knowledge-Creating Company: how Companies Create the Dynamics of Innovation. New York: Oxford University Press, 1995. 